Z. klin. Chem, u. klin. Biochem.

9. Jg., S. 402-404, Scptember 1971

\title{
Determination of Urinary Aromatic Acids by Gas Chromatography
}

\author{
Results from healthy infants and from patients with phenylketonuria \\ By J. A. Völlmin, H. R. Bosshard, M. Müller, S. Rampini and H. Ch. Cứtrus \\ Department of Pediatrics, University of Zürich, Kinderspital, Zürich, Switzerland
}

(Eingegangen am 13. Mai 1971)

\begin{abstract}
A gas chromatographic method for the quantitative determination of aromatic acids in human urine is described. Urine samples from 10 healthy infants and 6 untreated patients with phenylketonuria were analyzed for metabolites of phenylalanine and tyrosine. This procedure permits the quantitative determination of the following aromatic acids: Phenylacetic acid, mandelic acid, phenyllactic acid, $0-, m-$ and $p$-hydroxyphenylacetic acid, phenylpyruvic acid, $m$-hydroxyphenylhydracrylic acid, homovanillic acid, $p$-hydroxyphenyllactic acid, 3-methoxy-4-hydroxy-mandelic acid (vanillmandelic acid) and p-hydroxyphenylpyruvic acid. The identity of the aromatic acids is confirmed by mass spectrometry. Patients with phenylketonuria could easily be distinguished from healthy infants.
\end{abstract}

Es wird eine gaschromatographische Methode zur quantitativen Bestimmung von aromatischen Säuren im menschlichen Urin beschrieben. Urinproben von 10 gesunden und 6 unbehandelten Kindern mit Phenylketonurie wurden untersucht und die folgenden Metaboliten quantitativ ermittelt: Phenylessigsäure, Mandelsäure, Phenylmilchsäure, 0 -, $m$ - und $p$-Hydroxyphenylessigsäure, Phenylbrenżtraubensäure, $m$-Hydroxyphenylhydracrylsäure, Homovanillinsäure, p-Hydroxyphenylmilchsäure, 3=Methoxy-4-hydroxymandelsäure (Vanillinmandelsäure) und $p$-Hydroxyphenylbrenztraubensäure. Die Identifikation der Metaboliten erfolgte in einer Kombination Gaschromatographie/Massenspektrometrie. Patienten mit Phenylketonurie und gesunde Kinder unterscheiden sich in der Ausscheidung der aromatischen Säuren erheblich.

\section{Introduction}

The determination of aromatic acids in urine using paper chromatography was studied fundamentally by ARMSTRONG and coworkers $(1,2)$. Quantitative analysis of individual components, however, is not easy with this technique. Several authors have subsequently used gas chromatographic methods to quantitate urinary aromatic acids in various diseases (phenylketonuria $(3,4,5)$, tyrosinosis (6), alcaptonuria $(4,7)$, neuroblastoma $(3,4$, $8)$, cirrhosis of the liver (9), phaeochromocytoma $(8,9)$, cystic fibrosis (10) and others). With respect to phenylketonuria, the following metabolites in urine are highly increased: phenylacetic acid, phenyllactic acid, phenylpyruvic acid and o-hydroxyphenylacetic acid. This has been teviewed by KNox (11).

The present study compares the excretion of metabolites of phenylalanine and tyrosine in patients with phenylketonuria with that in healthy infants. Since the methods published $(3,4,5)$ for the determination of aromatic acids with gas chromatography do not allow in our experience a satisfactory separation, we used a modified technique for the present study.

\section{Procedures}

\section{Subjects}

Patients with phenylketonuria and normal subjects were children aged 10 days to 12 years. No special diet was observed during collection of urine samples.

Chemicals

Solvents of reagent grade were redistilled before use

Reference compounds were obtained from Fluka, Switzerland, Merck, W.-Germany and Schurchardt, W.-Germany. m-Hydroxy- phenylhydracrylic acid was a generous gift of Dr. M. D. ArmSTRONG.

Internal standard was 10 -undecenoic acid methyl ester $(100 \mathrm{mg}$ in $100 \mathrm{ml}$ pyridine).

Derivatives

Methylation was carried out with diazomethane according to VOGEL (12).

Trimetbylsilylation was carried out with the following mixture: pyridine: hexamethyldisilazane: trimethylchlorosilane 10:4:1 $(\mathrm{v} / \mathrm{v})$.

\section{Creatinine}

Urinary creatinine was determined according to JAFFÉ (13).

\section{Extraction}

Urine samples corresponding to $2.5 \mathrm{mg}$ creatinine were' diluted to $10 \mathrm{ml}$ with distilled water and adjusted to $\mathrm{pH} 1-2$ with $2 \mathrm{~N}$ $\mathrm{H}_{2} \mathrm{SO}_{4} .10 \mathrm{ml}$ of a saturated sodium chloride solution were added and the mixture was extracted 3 times with $10 \mathrm{ml}$ of ethyl acetate. The combined ethyl acetate solutions were re-extracted twice with $15 \mathrm{ml}$ of a $10 \%$ sodium bicarbonate solution. The combined bicarbonate solutions were adjusted to $\mathrm{pH} 2$ with conc. $\mathrm{HCl}$ and extracted 3 times with ethyl acetate. The solution was then dried over $\mathrm{Na}_{2} \mathrm{SO}_{4}$, filtered, concentrated on a rotary evaporator to about $2.5 \mathrm{ml}$ and transferred to a glass stoppered tube. The residue was transferred with another $2.5 \mathrm{ml}$ of ethyl acetate. $100 \mu \mathrm{l}$ of internal standard solution were added and the mixture was methylated for $2 \mathrm{~min}$. with $1 \mathrm{ml}$ of diazomethane in ether. The solution was concentrated with $\mathrm{N}_{2}$ at $40^{\circ}$ to about $100 \mu \mathrm{l}$. The methylated sample was silylated for $10 \mathrm{~min}$. with $0.5 \mathrm{ml}$ of silylation mixture at room temperature. The precipitate was centrifuged and $2 \mu \mathrm{l}$ of the supernatant were injected into the gas chromatograph.

\section{Gas chromatography}

A gas chromatograph Aerograph model 1520 with glass columns XE $603 \%$ on Gaschrom P 80-100 mesh ( $2 \mathrm{~m} \times 2.7 \mathrm{~mm} \mathrm{i.} \mathrm{d.)}$ was used. Carrier gas was $\mathrm{N}_{2}(40 \mathrm{ml} / \mathrm{min})$ and the apparatus was 
equipped with a flame ionization detector. The temperatures were as follows: Column: $4 \mathrm{~min} .120^{\circ}$, prog. $4^{\circ} \mathrm{min}$., $190^{\circ}$; injector: $250^{\circ}$; detector: $230^{\circ}$.

Gas chromatography - mass spectrometry (GC/MS)

For identification of the individual aromatic acids, a combination GC/MS LKB 9000 was used. Columns and conditions were identical with those described above.

\section{Calculations}

A calibration curve was obtained by subjecting the reference compounds to all steps of analysis. In this way, errors due to losses could be eliminated.

\section{Sensitivity}

The smallest amount distinguishable from zero in our procedure was $1 \mu \mathrm{g} / \mathrm{mg}$ creatinine, but with larger quantities of urine, a considerably higher sensitivity may be reached.

\section{Recovery}

When p-hydroxyphenylacetic acid was added to urine before extraction, the recovery in 10 separate determinations was about $80 \%$.

\section{Reproducibility}

The variation coefficient of 10 determinations in the same urine was $8.2 \%$.

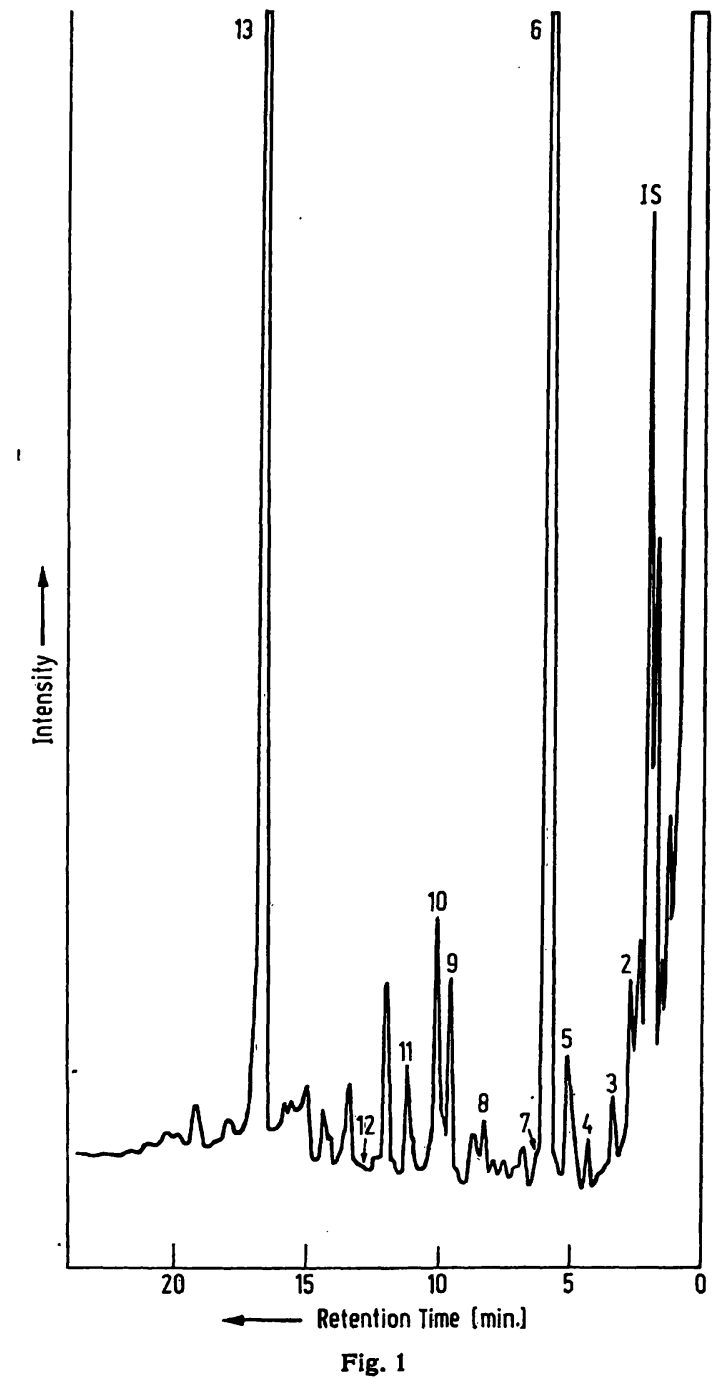

Gas-chromatographic separation of urinary aromatic acids from a normal infant (L. L.)

For explanation of the ciphers see table 1 is $=$ Internal Standard

\section{Results}

In figure 1 and 2 typical gas chromatograms of aromatic acids in the urine of a healthy infant and of a patient with phenylketonuria are shown. In table 1 , individual and mean values of 10 healthy infants and of 6 untreated patients with phenylketunuria are given. Phenylacetic acid, phenylpyruvic acid, phenyllactic acid, mandelic acid and o-hydroxy-phenylacetic acid were markedly increased in the urine of all patients with phenylketonuria. This is in agreement with other authors $(5,7)$. The remaining acids cited in table 1 were present in similar amounts in the urine of patients and of normal infants. Hippuric acid was found in all urinary samples, but was not determined quantitatively. All the aromatic acids studied were identified by comparing their retention behaviour and their mass spectra with reference compounds.

\section{Discussion}

Various derivatives for the gas chromatographic separation of aromatic acids have been described $(3,5)$. According to our experience, methyl ester/trimethylsilyl ether

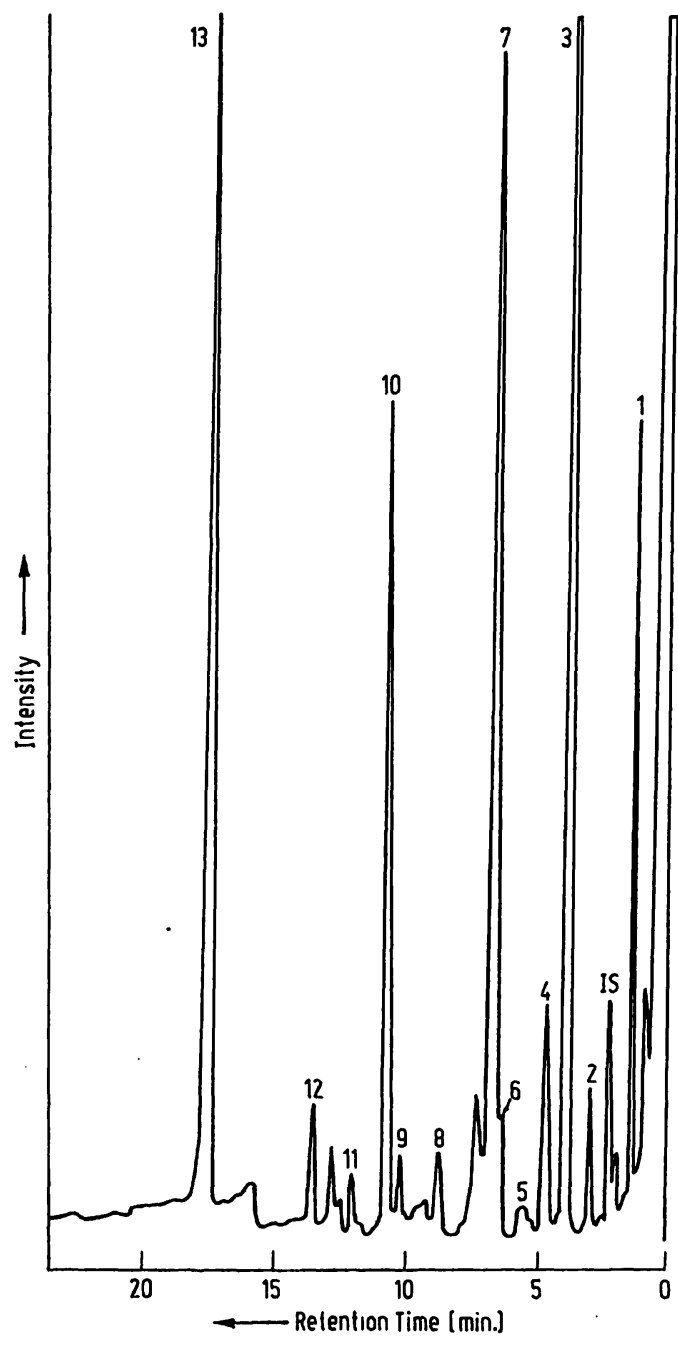

Fig. 2

Gas-chromatographic separation of urinary aromatic acids from a patient with phenylketonuria ( $R$. W.)

For explanation of the ciphers see table 1 is $=$ Internal Standard 


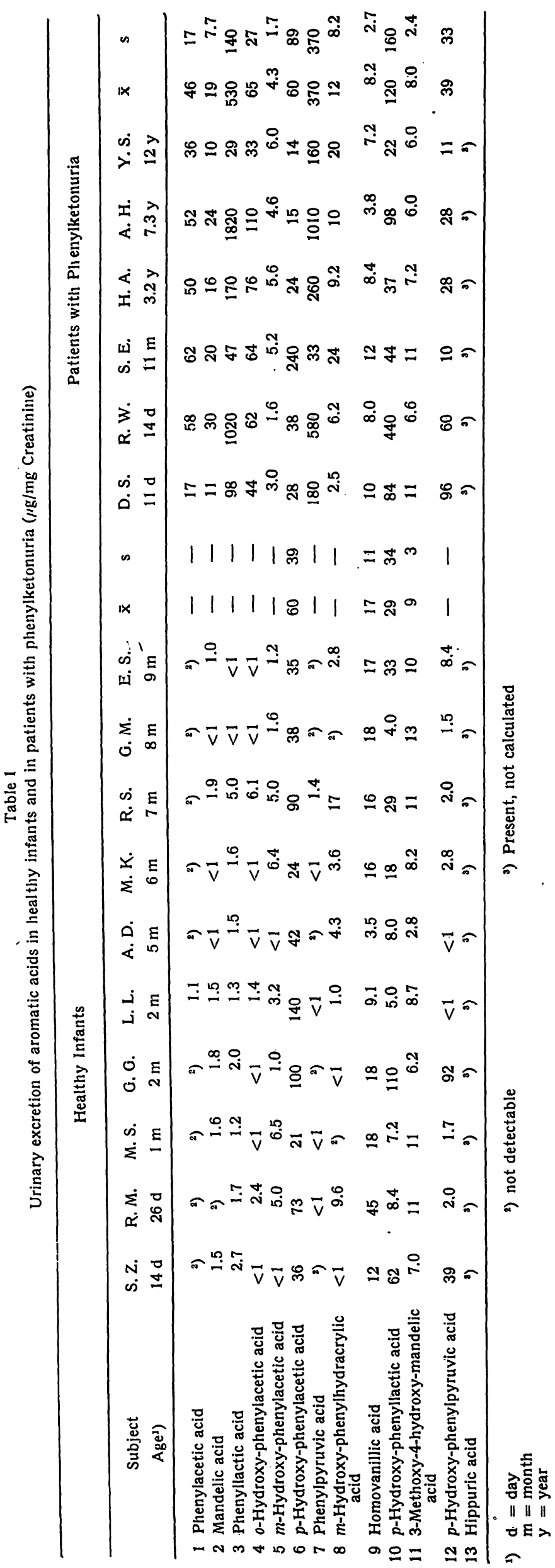

derivatives are very stable and give better gas chromatographic separation than e. g. trimethylsilyl ester/trimethylsilyl ether derivatives. For the separation of aromatic acids various stationary phases (SE-30, SE-52, OV-17, EGS etc.) are in common use. In our hands, however, columns coated with XE-60 give the best results. A combination of gas chromatograph/mass spectrometer appears to be particularly useful for the identification of unknown aromatic acids.

The high excretion of aromatic acids in infants with phenylketonuria allows them to be easily distinguished from healthy infants. The presented values for the patients with phenylketonuria are in good agreement with those found by KNOX (10).

In conclusion, by means of the method described, it is possible to determine the different aromatic acids with high specificity in a relatively short time. The method is equally convenient for the study of other diseases associated with disorders of the aromatic acid metabolism.

\section{Acknowledgements}

The authors are grateful to Dr. K. BAERLOCHER for reviewing the manuscript and to Miss $H$. Karpf, Mr. M. Elsener, Mr. U. LIEBerherR und Mr. R. GitZELmanN for skillful technical assistance.

\section{References}

1. Armstrong, M. D., K. N. F. Shaw and P. E, Wall, J. biol. Chemistry 218, 293 (1956). - 2. Armstrong, M. D., K. N. F. Shaw, M. J. Gortatowskr and H. Singer, J. biol. Chemistry 223, 17 (1958). - 3. Wrlliams, C. M. and C. C. SweEleY, in Biomedical Applications of Gas Chromatography, H. A. Szymanski, Ed., Plenum Press, New York (1964), p. 225. - 4. Karoum, F., C. O. ANah, C. R. J. RuthVen and M. SANDler, Clin. chim. Acta, Amsterdam 24, 341 (1969). - 5. BlaU, K., Clin. chim. Acta, Amsterdam 27, 5 (1970). - 6. GeNtz, J., B. Lindblad, S. Lindstedt, L. Levy, W. Shasteen and R. Zettekström, Amer. J. Dis. Child. 113, 31 (1967). - 7. KNox, W. E. and K. M. LeMAY, Biochem. J. 49, 686 (1951). - 8. KARóum, F., C. R. J. Ruthven and M. SAndier, Clin. chim. Acta, Amsterdam 20, 427 (1968). - 9. Ruge, W., this journal 6, 448 (1968). 10. Van der Heiden, C., S. K. Wadman, D. Ketring and P. K. DE BREE, Clin. chim. Acta, Amsterdam 31, 133 (1971). - 11. KNox, W. E., in Metabolic Basis of Inherited Disease, Stanbury, J. B., J. B. Wyngaarden and D. S. Fredrickson, Eds., Mc GrawHill (1966), p. 258. - 12. Vogerl, A. I., Practical Organic Chemistry, Longmans (1964), p. 971. - 13. JAFFÉ, M., HoppeSeylers Z. physiol. Chem. 10, 399 (1886); Natelson, S. Microtechniques of Clinical Chemistry, p. 196. Charles C. Thomas Publ., Springfield Ill. (1961).

Priv.-Doz. Dr. H.-Ch. Curtius Kinderspital CH-8032 Zürich Steinwiesstr. 75 